McArthur, D., Thorsen, I., and Ubøe, J. (2010) A micro-simulation approach to modelling spatial unemployment disparities. Growth and Change, 41 (3). pp. 374-402. ISSN 0017-4815.

Copyright (C) 2010 The Authors

A copy can be downloaded for personal non-commercial research or study, without prior permission or charge

Content must not be changed in any way or reproduced in any format or medium without the formal permission of the copyright holder(s)

When referring to this work, full bibliographic details must be given

http://eprints.gla.ac.uk/99520

Deposited on: 28 November 2014

Enlighten - Research publications by members of the University of Glasgow http://eprints.gla.ac.uk 


\section{A micro-simulation approach to modelling spatial unemployment disparities}

This paper aims to construct a comprehensive model capable of simulating spatial unemployment disparities. The key feature of the model is that it simultaneously deals with commuting and migration. Much of the existing literature simply models one adjustment mechanism at a time. This paper adopts a micro-simulation approach to build a model which can deal with equilibrium and disequilibrium unemployment disparities in a context where commuting and migration are possible. The model is then used to demonstrate the importance of considering both types of flows and to guide future empirical and theoretical work in the area.

Keywords: Spatial unemployment disparities, micro-simulation approach, Regional amenities, Residential site preference, Spatial Interaction

JEL codes: J6, R12, R23 


\section{Introduction}

It is well known in the literature that unemployment rates tend to vary systematically between regions. Partridge and Rickman (1997a) found significant levels of dispersion in US state unemployment rates in the 1970s and 1990s. Evans and McCormick (1994) studied changes in the regional pattern of unemployment in the UK since the 1970s. Utilising results from OECD-studies, they begin their analysis with the observation that regional unemployment differentials have been strikingly persistent for a very long period, both in the UK and in other OECD countries. Elhorst (2003) provides a review of the unemployment disparities literature.

Blanchard and Katz (1992) discuss mechanisms which can operate to close such disparities. The three primary mechanisms are: wage adjustments, out migration of unemployed workers and the movement of firms into low-wage/high unemployment areas. In some cases, these mechanisms close any disparities which arise in a relatively short period of time. Unemployment disparities of this type are known as disequilibrium disparities. However, the cases where the disparity persists for a long period of time requires alternative explanations. These explanations fall into the category of equilibrium disparity theories. Equilibrium explanations allow for disparities to persist. Both types are mentioned by Blanchard and Katz (1992) but with an emphasis on the disequilibrium aspect.

One of the problems with the current literature, some of which is outlined in Section 2, is that the approaches tend to focus on only one explanation at a time, i.e. on equilibrium or disequilibrium explanations. An additional simplifying assumption which is usually invoked is that either commuting or migration is impossible. This assumption is made in the interests of analytical tractability even though there is a clear simultaneity between migration and commuting (see, for instance, van Ommeren et al. (1999)). These assumptions limit the situations which can be explored using such models as well as imposing uncertainty on any conclusions reached. It is the ambition of this paper to simultaneously model migration, commuting, 
employment decisions, frictions in the equilibrating forces and equilibrium explanations of regional unemployment rates. These are basic concepts within regional labour market analysis but even with a high number of simplifying assumptions, such a model would be analytically intractable. To deal with this, inspiration from the agent-based computational economics (ACE) literature was sought (Testfatsion, 2003; Epstein, 1999).

The agent-based methodology is, in essence, a simulation based approach. It aims to model macroeconomic phenomena by allowing autonomous agents with given behavioural rules to interact. These micro interactions create macro phenomena, as in the real world. The approach is primarily concerned with dynamics, simple heuristic behavioural rules and bounded rationality. This model developed in this paper more closely follows a neoclassical approach than an ACE approach, but does still simulate the actions of individual agents. A two region economy populated by an artificial society of heterogeneous, utility maximising agents was created. The model allows the exploration of the relative strength of various factors in the adjustment process as well as giving an understanding of when and why persistent unemployment disparities arise. It is hoped that the model will provide useful input into future empirical work in the field. This could take the form of providing prior information on the likely value of various parameters and time scales, as well as allowing the testing of different model specifications and estimation techniques.

The paper is structured as follows. Section 2 reviews the literature relating to unemployment disparities. The theory outlined in this review underpins the model presented in Section 3. Section 4 explores the features of the model through a series of experiments. Section 5 presents an empirical example of unemployment disparities from south west Norway. Policy insights gained from the simulation model will also be discussed in this section. Section 6 closes with some concluding remarks.

\section{Regional unemployment disparities}

A brief review of the literature on spatial unemployment disparities will be presented in this section 
to provide a foundation for the model presented later. The discussion is divided into equilibrium and disequilibrium explanations. Equilibrium disparities can be further divided into two categories based on different traditions in the literature: expected wage explanations (Harris and Todaro, 1970) and amenity based explanations (Marston, 1985). This paper will construct a framework which is capable of modelling all of these explanations.

\subsection{Disequilibrium unemployment disparities}

A comprehensive treatment of disequilibrium disparities is given by Blanchard and Katz (1992) in their work on spatial unemployment disparities in the US. In their model, regions may persistently have different unemployment rates but the ratio of these differences depends on underlying factors which are given little attention. It is suggested that they may relate to amenities e.g. it might be expected that California may have higher relative unemployment due to its favourable climate and attractiveness to workers. This ratio, however, should be stable over time and not altered by employment shocks. In their model, disparities created by shocks are quickly eliminated by migration flows, firm relocations and wage adjustments. However, there is significant evidence from many countries that such disparities are not eliminated quickly, and persist in the long run. The main reason for persistent differentials in this framework would be frictions in the system preventing the equilibrating mechanisms from working.

\subsubsection{Migration}

The main evidence on migration comes largely from the US and Europe with results differing significantly. Puhani (2001) studied labour mobility within the European Union and found that migration did not play a significant role in the adjustment of the economy following a regional shock. Fidrmuc (2004) found that while wage differentials are statistically significant in determining the flow of migrants in the EU transition countries, the overall effect of the migration is negligible. Decressin and Fátas (1995) compared Europe to the US and found that changes in relative labour demand tend to be met by migration in the US but 
that in Europe they are met with changes in the participation rate. Bentivogli and Pagano (1999) also compared the US and EU. They found that migration is much more influenced by wage differentials in the US than in Europe. In the EU, migration is more sensitive to a wage risk. They also found that migration is unresponsive to rising unemployment in Europe but not in the US.

In the model presented by Blanchard and Katz (1992), much of the regional adjustment which takes place is attributed to migration. However, several aspects of the modelling framework have since been questioned. Rowthorn and Glyn (2006) highlight the importance of measurement errors in time series data. After adjusting for the likely magnitude of such errors, they find that migration has played a much smaller role in the last 20 years in the US than was previously believed. They suggest that it may have played a more important role in the 1950s and 60s when agriculture played a greater role in the economy and a reserve of farm workers were available to migrate to more vibrant labour markets. Partridge and Rickman (2006) find non-stationarity in state employment rates and conclude that the role of migration was overstated by Blanchard and Katz. Bartik (1993) experiments with the specification of the Blanchard and Katz model and also finds evidence of non-stationarity in employment rates.

\subsubsection{Firm relocations}

Maoh and Kanaroglou (2007) provided a recent review of the literature on firm relocation decisions. Some of the main points are that firms prefer to stay in their present location if possible (Bade, 1983), fairly significant regional deficiencies are required to induce a firm to move (Van Wissen 2000) and that the main determinates of moving decisions are internal factors (Brouwer et al, 2004). Maoh and Kanaroglou (2007) also found that when most firms moved, they tended to move only a short distance, usually within the same region. Alternative theoretical explanations of firm behaviour are presented by van Dijk and Pellenbarg (2000), in which firms are less responsive to local labour market conditions. Diamond and Simon (1990) even find evidence that many firms prefer to locate in high wage cities in order to benefit from agglomeration effects. This is consistent with the findings of Blanchard and Katz (1992) who found that firms moving into low 
wage areas played only a small role in the elimination of unemployment disparities.

\subsubsection{Wage flexibility}

Jimeno and Bentolila (1998) examined the problem of persistent regional unemployment in Spain between 1976 and 1994. They found that wages were very unresponsive to any regional economic conditions. They believed this was caused by union power and centralised wage setting. In a study of differences between EU regions, Abraham (1996) found that wages showed little sign of adjusting after a shock and that inter-regional migration was very low compared with the US. Buettner (2007) found that it took the old EU-15 countries around twice as long to adjust to a shock as the new EU accession countries. Siebert (1997) also concluded that wages in the EU failed to adjust to labour market conditions.

The model in Blanchard and Katz (1992) allows average relative wages to differ across states but assumes that relative wages are stationary. They find that flexibility in wages reduces the effects of an employment shock but that the effect on job creation and firm relocations is weak. Using structural vector autoregressive models (SVAR), Partridge and Rickman (2003) and Partridge and Rickman (2007) find short-run wage flexibility in the USA and Canada respectively.

\subsubsection{Commuting}

Commuting is ignored in much of the literature relating to unemployment disparities. Partly this is due to how regions are defined. It is common to define regions in such a way that commuting flows between the regions are minimal and can be ignored. There are reasons to be suspicious of this logic. Apart from being difficult to define such regions, it is often more interesting to look at administrative regions e.g. the States within the US. Such divisions were not designed to minimise commuting flows. Secondly, as Green et al. (1999, p. 1) observe, "research on commuting patterns has revealed a trend towards longer, and more geographically diverse, journey-to-work flows". They are not alone in this observation. Schafer and Victor (2000) note that the increasing wealth and improvements in transportation infrastructure are increasing the distances which workers are willing and able to commute. The ability to work from home and commute on a 
weekly or monthly basis also increases the distances over which commuting can occur (Green et al., 1999). Based on Swedish data, Sandow (2008) illustrates that flows of daily commuting are observed even at distances of $200-400 \mathrm{~km}$.

In a county level model of North Carolina, Renkow (2003) found that $70-80 \%$ of employment growth during the 1980s was accommodated by changes in flows of commuters rather than migration. The analysis is extended in Renkow (2006) where a county level model covering the 13 southern states is estimated. The finding was that $60-70 \%$ of employment growth in the 1990 s was accomodated by changes in commuting. A review of both of these papers is presented in Renkow (2007). In particular, the role of commuting as a leakage or spatial spillover is highlighted. Using U.S. county level data, Partridge et al. (2009) also found that commuting dominates the adjustment process. With commuting appearing to play such an important role in the adjustment process, it seems unreasonable to ignore it in an analysis of regional labour markets.

\subsection{Equilibrium unemployment disparities}

Rather than focusing on equilibrating mechanisms and the speed of adjustment after an employment shock, the equilibrium disparities class of models focus on explaining reasons for persistent disparities which persist even when equilibrating mechanisms are operating. Equilibrium disparities fall into two main traditions in the literature: the expected wages hypothesis and the amenities theory.

\subsubsection{Expected wages}

Harris and Todaro (1970) describe disparities as arising from differences in the expected wage rather than absolute values of unemployment and wages. Their work takes place in the context of developing economies although is also relevant in other cases. They model a two sector economy where workers can choose to migrate from a low unemployment rural area to a high unemployment urban area. In the model, the wages in the urban sector are higher than in the rural sector. People may choose to migrate from the rural to urban despite the higher level of unemployment in the urban sector because the expected wage is higher 
in the urban sector. The key point here is that even though the risk of unemployment is higher, migration is optimal because this is compensated for by higher wages. Only when the expected wage is equal in both areas does migration cease. This equilibrium does not require an even distribution of unemployment or equal wages in both regions.

Partridge and Rickman (1997b) investigate the claim that the wage curve (Blanchflower and Oswald, 1994), which postulates a negative relationship between wages and unemployment, invalidates the Harris-Todaro model. After experimenting with several specifications and datasets, they find that generally there is a positive relationship between wages and unemployment and that a negative relationship was found in certain cases. They conclude that the findings on the wage curve do not provide sufficient evidence to disregard the Harris-Todaro model. Using data only recently made available, Mulhern and Watson (2009) find that a Harris-Todaro process now plays an important role in determining internal migration patterns in Spain.

\subsubsection{Amenity theories}

In the model developed by Marston (1985), rather than considering the wage rate alone, workers consider the total utility of living in a particular area. Their utility is a function of wages, as in the traditional approaches, and also of the area amenities or characteristics. In this model, a worker may choose to live in an area with high unemployment because they are compensated by the amenities offered by the region. For this reason, it would be expected that a region with high amenity value would have a higher unemployment rate and therefore lower expected wages.

Marston (1985) and Partridge and Rickman (1997a) presents empirical evidence using US data to support the amenity theory of migration. Using Russian panel data, Berger et al. (2008) find evidence of compensating differentials in labour and housing markets within Russia. López-Bazo et al. (2005) find that an uneven distribution of amenities plays a significant role in maintaining regional unemployment disparities in Spain and that disequilibrium factors play a less important role. Partridge and Rickman (2007) study the role of regional amenities in explaining migration flows in Canada. They find that migration is primarily determined 
by labour demand shocks. In contrast, they find that amenities play an important role in the determination of migration flows in the US (Partridge and Rickman, 2006). Tuck et al. (2009) study the effect of amenities on teacher salaries in the US. They find that school districts with a high level of amenities find it easier to recruit and retain staff as a result of the region being more attractive to workers.

\section{The model ${ }^{1}$}

\subsection{Demographics}

The intractability of an analytical model allowing simultaneous commuting and migration makes an agent based approach a natural choice. The model constructed in this paper will be an essentially neoclassical in style i.e. agents will act to maximise their utility function rather than behave according to a simple set of behavioural rules as is often the case in the standard agent based computational approach.

The first stage is to define a geography. In this paper, a geography with only two regions is considered. The distance between these can be varied continuously to investigate the impact of distance on regional development. Working with only two regions makes the presentation of results easier and also makes it easier to separate the effects of distance and spatial structure. It is worth noting that this modelling approach can be extended to an arbitrary number of regions.

Next in the modelling process is to define a set of agents. There are a number of ways in which this can be achieved. Agents with an infinite lifespan could be used, or a set of agents with random characteristics, for example. The approach selected in this paper is to base the demographic development of the agents on Norwegian statistical data. With this approach, an initial set of agents is defined. All of these agents are 15 years old and single. Allowing the system to evolve according to a given set of statistics will generate a population demographically identical to that of Norway and will wipe out all traces of the initial conditions. One of the advantages of this approach is that it allows the effects of changes in these statistics to be

\footnotetext{
1 The code (written in Mathematica) for the model is available from the authors upon request.
} 
modelled e.g. what would happen if the divorce rate fell or life expectancy increased. It is also as easy to implement as any of the alternatives.

The rules in the model are as follows. Any adult woman in the model can give birth with the probability of doing so being conditional on age. The sex of a child is determined randomly. If the woman is not married, the father is drawn randomly from the population of single men. Children are converted to adults when they reach the age of 15 . At the age of 70 , people are retired. Adults can marry, divorce, have children and apply for work. Mortality rates are based on standard life insurance tables, using Gompertz-Makeham's law i.e. that the death intensity of a man of age $x$ is given by the function:

$$
\mu=a+b c^{x} \text { where } a=0.9, b=4.4 \cdot 10^{-5} \text { and } c=1.10154
$$

Death rates of women are adjusted by a 3 year age correction. Single agents can get married with the probability being conditional on age, sex and previous marital status. Spouses are drawn from the population of single people. As the concern of this paper is regional interaction, attention must be given to the geographical aspect of marriage. Rosenzweig and Stark (1989) highlight the importance of marriage in explaining regional migration patterns in low income countries. It is reasonable to assume that the chance of two arbitrary people meeting is a declining function of the distance between the areas in which they live. It is therefore more likely that marriages will occur within a region than across regions. In this paper, the chances of marrying a person in another region is assumed to decline exponentially.

$$
\max \left[e^{-\sigma \cdot d}, 0.01\right]
$$

Here, $d$ is the distance between the zones and $\sigma$ is a parameter controlling how quickly the probability declines with distance. This functional form was chosen so that the probability falls with distance but never reaches zero. This reflects the fact that it is possible for two people to meet by chance irrespective of the distance between the areas in which they live. When a couple marries, they move in together along with any children they already have. Married adults can get divorced with probabilities being conditional on age and sex. 


\subsection{Utility functions}

Agents in the model act to maximise their utility functions. The most obvious component of the utility function is the wage. Workers consume their earnings and derive utility from this consumption. There is a problem with including only money in the utility function. Consider a situation where a worker can choose between commuting and migrating. Commuting is expensive therefore a move would be preferred. If transaction costs are incurred in the moving process (as in this model), then this effect will be reduced slightly. However, it still seems unreasonable to assume that workers have no innate preferences for where they would rather live. In this paper residential preferences are assumed to take two forms. The first way is through the presence of an area specific amenity (disamenity) which is attractive (unattractive) to all agents. The second form, identified by Partridge and Rickman (1997a), is a preference for the region of birth. This preference may be related to childhood experiences as well social familiarity with a community. It could also represent region specific human capital. These factors could be combined in many different ways and easily included in the model. In this paper, the utility function is assumed to take a Cobb-Douglas form:

$$
U_{\alpha \beta}(V, \Omega, d)=(V+\Omega)\left(e^{-\alpha d}\right)^{\beta}
$$

$V$ represents wages net of any commuting costs, $\Omega$ represents the willingness to pay for a location-specific amenity attached to a region, $d$ is the distance between an agent's region of birth and residence. The parameters $\alpha$ and $\beta$ represent the strength of the agent's preference to live in the region in which they were born. The parameter $\beta$ is randomly drawn from a uniform distribution over the interval $(0.5,1)$. The birth region residential preference enters the function exponentially. This means that utility declines with distance but will never reach zero, allowing for the possibility that some individuals will be willing to migrate over a long distance. All agents in the model have different preferences with respect to where they want to live. Some agents care very little while others are less willing to migrate.

\subsection{Commuting, migration and employment decisions}


To simplify the analysis, a situation with homogeneous workers is considered where any agent of working age can apply for work. It is easy to expand the model to consider a situation with heterogeneous jobs and workers. An agent only applies for work if they will experience a net gain in utility. Successful applicants are randomly selected with unfilled vacancies carried over to the next period.

Agents who do not have employment will receive an unemployment insurance payment. Agents will apply for and accept a job if they can increase their utility by doing so. When an agent considers moving, they compare the expected utility of living in each region. The probability of gaining employment is based on the average unemployment rate in each of the regions over the past twelve months. This gives two probabilities, $p_{1}$ and $p_{2}$. Agents use these probabilities to calculate the expected utility of living in a region. Workers in the model are myopic and assume that these probabilities are constant over time. In addition, they do not forecast future wage development. It would certainly be possible, and interesting, to model different type of expectations but this lies beyond the scope of this paper. A discount rate of $7 \%$ is used.

This mechanism highlights the importance of the demographic section of the model. The utilities calculated by the agents will depend on their age, expected lifetime, marital status etc. This ensures that the model does not result in all agents deciding to undertake the same action i.e. not all agents will move from one region to another because the unemployment rate in the other region is slightly lower. This seems intuitively reasonable. It is also one of the reasons why the model economy takes time to adjust. New workers entering the labour force may be willing to migrate at the start of their working career, while older workers may prefer to remain in a high unemployment region. It may take several cohorts of these workers entering the labour force and several cohorts of older workers leaving for a disparity to be eliminated.

To understand in more depth how agents decide on which actions to undertake, an example is presented here. Assume that a person with age $t$ is unemployed, let $w_{0}$ denote unemployment insurance and let $w_{1}$ and $w_{2}$ denote the salaries (net of commuting costs) in the two zones. If $w_{0}<\min \left[w_{1}, w_{2}\right]$ and $w_{1}<w_{2}$, then the transition matrix, $M$, can be computed as follows: 


$$
M=\left[\begin{array}{lll}
1-p_{1}-p_{2}+p_{1} p_{2} & p_{1}-p_{1} p_{2} & p_{2} \\
0 & 1-p_{2} & p_{2} \\
0 & 0 & 1
\end{array}\right]
$$

$M_{i j}$ is the probability of making a transition from state $i$ to state $j$ for $i, j=1,2,3$ where state 1 is unemployment, state 2 is employment in Region 1 and state 3 is employment in Region 2. For example, $M_{13}$ is the probability that an unemployed worker gets a job offer in Region 2. Since Region 2 is the region offering the highest wages net of commuting costs, $M_{13}=p_{2}$. If an unemployed worker gets a job offer in Region 1 , however, he/she will reject that offer if he/she simultaneously gets an offer in Region 2 . Hence, $M_{12}=p_{1}-$ $p_{1} * p_{2} . M_{11}$ is the complement of the two previous probabilities, hence $M_{11}=1-\left(p_{1}-p_{1} * p_{2}+p_{2}\right)$. The remaining elements are based on the same logic. The expected salary $S_{i}$ after $i$ years is then given by the expression:

$$
S_{i}=\left(M^{i}\left[\begin{array}{l}
w_{0} \\
w_{1} \\
w_{2}
\end{array}\right]\right)^{(1)}
$$

where the superscript 1 means that the first component of the vector inside the brackets is computed. Retirement takes place after the individual has reached 70 years of age. The total expected salary is then given by the expression:

$$
V_{0}=\sum_{i=0}^{70-t} S_{i} \cdot e^{-\rho i}+\sum_{i=70-t+1}^{T_{t}} S_{70-t} \cdot e^{-\rho i} \cdot 0.66
$$

Here $S_{70-t}$ is the expected salary at the time of retirement. In Norway the pension is typically $66 \%$ of that value. $T_{t}$ is the expected remaining lifetime of a person of age $t$. The value of $T_{t}$ is computed using Gompertz-Makeham's law. The individual then computes:

$$
V_{1}=\sum_{i=0}^{70-t} S_{i} \cdot e^{-\rho i}+\sum_{i=70-t+1}^{T_{t}} S_{70-t} \cdot e^{-\rho i} \cdot 0.66-m
$$

Here, $m$ is the cost of moving. This redefines the salaries net of commuting cost, so all the components in Equation (5) must be updated. An individual considering moving computes the monetary values $V_{0}$ and $V_{1}$ above. Then he or she computes location values $W_{0}$ (using present address) and $W_{1}$ 
(using alternative address). The next stage is to compute the two utility values $U_{\alpha, \beta}\left(V_{0}, W_{0}\right)$ and $U_{\alpha, \beta}\left(V_{1}, W_{1}\right)$. If the person is unmarried, he or she decides to move if $U_{\alpha, \beta}\left(V_{1}, W_{1}\right)>U_{\alpha, \beta}\left(V_{0}, W_{0}\right)$. If the person is married, however, the same calculation is carried out for the spouse. The results are added and the couple moves if the alternative location provides a larger total utility. The utility of both spouses is given equal weight.

\subsection{Wages and the demand for labour}

The simulation framework means that it is possible to model almost any kind of wage setting behaviour. As the main focus of this paper is unemployment disparities, a simple wage setting mechanism which reproduces the kind of wage adjustment shown in Blanchard and Katz (1992) is used. A Phillips curve style mechanism achieves this.

$$
w_{i}^{(t)}=w_{i}^{(t-1)}\left(1+\frac{U_{i}^{(t)}-U_{i}^{(t-1)}}{U_{i}^{(t-1)}}\right)^{-\lambda}, \lambda>0, i=1,2
$$

Here, $w$ is the wage and $U$ is the unemployment rate. The subscript $i$ denotes the region while $\lambda$ models the sensitivity of wages to changes in the level of unemployment. In our numerical experiments it is set to a value of 0.1 . It is worth noting that this wage setting mechanism is not the same as that presented in Blanchard and Katz (1992), which is based on unemployment disparities between regions rather than unemployment within one region. The results achieved using the Philips curve mechanism give similar results to the mechanism in Blanchard and Katz (1992) in that rising unemployment causes a decline in wages and a modest increase in employment opportunities. The demand for labour is initially set to give an unemployment rate of $5 \%$. This represents a natural rate of unemployment. This rate is then modified according to exogenous shocks and movements in wages and the labour supply in each region. Demand for labour as a percentage of the workforce $(\ell)$ in each region changes according to the following expression.

$$
\ell_{i}^{(t)}=\ell_{1}^{(t-1)}\left(1+\frac{w_{i}^{(t)}-w_{i}^{(t-1)}}{w_{i}^{(t-1)}}\right)^{-\eta\left(w_{i}^{(t-1)}, w_{i}^{(t)}\right)} \eta>0, i=1,2
$$




$$
\eta\left(w_{i}^{(t-1)}, w_{i}^{(t)}\right)\left\{\begin{array}{l}
\eta_{1} \text { if } w_{i}^{(t-1)} \leq w_{i}^{(t)} \\
\eta_{2} \text { if } w_{i}^{(t-1)}>w_{i}^{(t)}
\end{array}\right.
$$

The parameter $\eta\left(w_{i}^{(t-1)}, w_{i}^{(t)}\right)$ is larger when wages are rising than when they fall. This increases friction in the system by allowing the job destruction rate to exceed the job creation rate in response to movements in the wage rate.

A summary of the value of various parameters and variables can be found in Appendix A.

\section{Simulation experiments}

The incredible flexibility of the simulation approach means that it is possible to simulate and explore an infinite number of scenarios. The experiments presented in this section will focus on some of the most commonly cited reasons for unemployment disparities. The simultaneity between migration and commuting will also be considered. This will highlight the importance of considering both mechanisms when modelling unemployment disparities.

The results presented below are examples from a much larger number of experiments which were run. Each simulation run contains a degree of random noise. To control for this, each experiment was run 25 times with a different random seed each time. This allows the average realisation to be presented. Adding additional runs had only a minor effect on this average. In the absence of amenities, there is no reason for agents to choose to live in one region over another. As a result, this averaging procedure gives an even distribution of population between the regions. Prior to the introduction of shocks to the system, employment opportunities are also distribute symmetrically. This means that in the average realisation, there is no unemployment disparity.

\subsection{Commuting, Migration and Residential Site Preferences}

One particularly interesting experiment is to see what differences are observed when unreasonable assumptions are made concerning commuting behaviour. Figure 1 shows what happens to unemployment 
disparities when an employment shock is introduced into one of the regions for a commuting cost of 2.5 NOK per $\mathrm{km}$ and then for 5 NOK per $\mathrm{km}$ and in an economy with $80 \mathrm{~km}$ between its two regions. A cost of 5 NOK per $\mathrm{km}$ (double what would be considered a reasonable estimate of commuting costs) makes commuting too expensive in most circumstances for agents in the model, at least when there are $80 \mathrm{~km}$ between the regions. This is analogous to assuming that commuting plays only a minor role in the adjustment process.

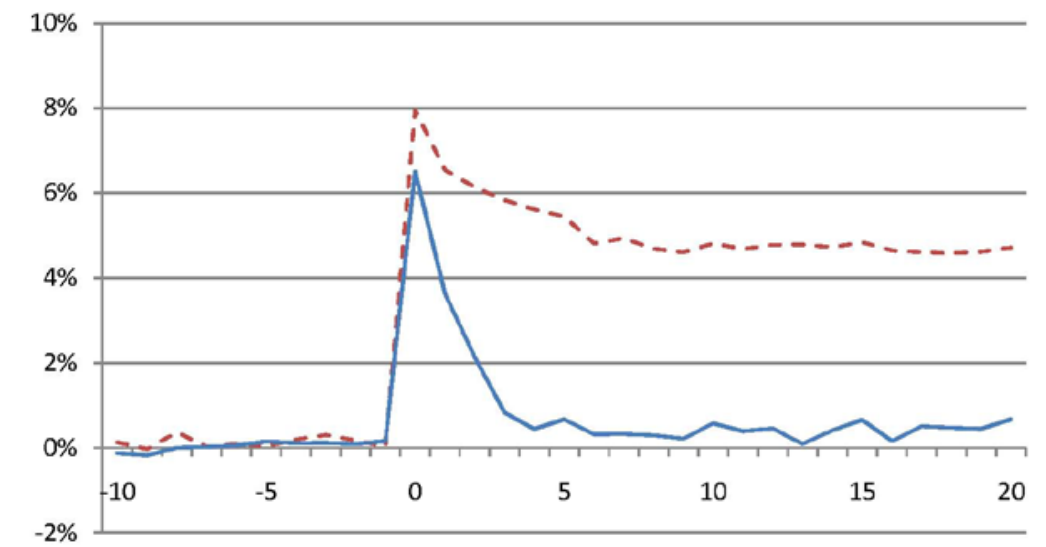

Figure 1: Unemployment differential with a $10 \%$ adverse employment shock introduced into Region 1 at year 0 . The dashed line shows the situation with a commuting cost equal to 5 NOK per $\mathrm{km}$ with the unbroken line showing the result for a commuting cost of 2.5 NOK per km.

The difference between the two scenarios is clear. When commuting is affordable to everyone there is no significant disparity in the medium to long term (as shown in the unbroken line) as commuting flows play an important role in the adjustment to the shock. The only disparity created is a disequilibrium disparity which is closed after around 5 years. When the cost of commuting is increased, the results are very different. The shock to Region 1 causes a large disparity to appear. After the initial shock, some adjustment takes place. This adjustment takes the form of workers migrating from Region 1 to Region 2 . This is partly induced by the unemployment disparity and partly by the wage disparity created by the unemployment shock. However, around 6 years after the shock, the adjustment process stops and the economy arrives at a new equilibrium position with an unemployment disparity of just under 5 percentage points. The ability of the model to discriminate between disequilibrium and equilibrium disparities is another strength of the modelling approach. A disequilibrium disparity does emerge, as in the previous case, but is closed after the first 6 years 
with only an equilibrium disparity remaining. In an empirical setting, Blanchard and Katz (1992) found that disequilibrium disparities were eliminated after 6 years.

It is interesting to consider the nature of the equilibrium disparity which emerges in Figure 1 . In Blanchard and Katz (1992), once disequilibrium disparities are eliminated, the ratio of unemployment rates between regions returns to its original value. This ratio is determined by the ratio of amenities between regions. This cannot directly be the explanation because there are no region specific amenities in the example in Figure 0. Agents do, however, have a preference to live in the region in which they were born. At first it is difficult to see how this can be responsible for a change in the ratio of unemployment rates between the regions since preferences for where to live have remained constant.

To understand why, consideration must be given to the agents' utility functions. Agents derive utility from their income (which is a function of their employment status and wage) and their location in relation to where they were born. Prior to the employment shock, there are no disparities between the regions in terms of employment opportunities, wages, population or unemployment. Under these conditions there are no factors present which would create a disparity. When the employment shock is introduced, this changes and there is an incentive to move from the high unemployment region to the low unemployment region. However, the incentive for agents in Region 1 to move must be traded off against the loss of utility from migrating out of their home region. For some agents, this preference is low and they are willing to migrate for even a small increase in the expected wage in Region 2. For others, however, their preference to remain in their home region is stronger than the incentive to move. Once the pool of labour which is willing to move is exhausted, the unemployment disparity which remains represents a new equilibrium. This idea can be shown diagrammatically and is presented in Figure 2. 


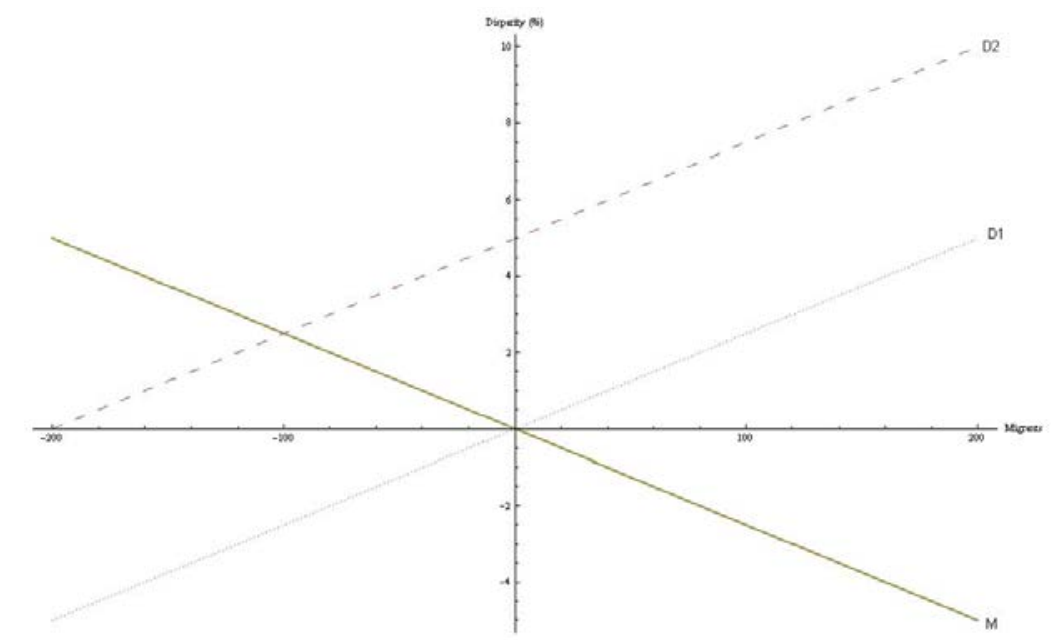

Figure 2: The small dashed line gives the unemployment disparity as a function of the number of migrants $(D 1)$, the large dashed line gives the unemployment disparity as a function of the number of migrants after a change in the distribution of employment $(D 2)$ and the solid line shows migration as a function of unemployment disparities $(M)$.

It is important to note that Figure 2 represents abstract reasoning based on the model results rather than a component of the model. The vertical axis shows the level of unemployment disparity between 2 regions with the horizontal axis showing the number of migrants living in a particular region. The $D$ curve show how changes in the distribution of the population create unemployment disparities. The $M$ curve shows how migration will respond to a given unemployment disparity. The position of the $D$ curve is determined by the distribution of workplaces with its slope determined by the ability of each region to absorb new migrants into its labour market. The position of the $\mathrm{M}$ curve is determined by the initial distribution of the population in the geography and location specific amenities. Its slope is determined by residential site preferences, moving costs and commuting opportunities (assumed not to exist for the purposes of this example).

In the diagram, the economy begins at the intersection of $D 1$ and $M$. At this level there is no disparity and no migration. This corresponds to a situation where population and jobs are evenly distributed and there is no incentive for agents to migrate. Consider an employment shock which creates an asymmetry in employment opportunities. This corresponds to a shift from $D 1$ to $D 2$. To maintain an economy with no disparities requires 200 migrants i.e. where the intersection of $D 2$ and the horizontal axis. However, if agents have a reluctance to move, the actual migration response will be lower. In the example shown, the 
migration response is limited to 100 . An equilibrium can only be created at this point with an unemployment disparity of 2.5 percentage points.

Returning attention to the simulation model, in the new equilibrium position the combination of the unemployment and wage disparity represents the willingness to pay of the marginal unemployed agent to remain in their birth region. There will be frictional adjustment around this new equilibrium as old workers leave the workforce and new workers enter it, but so long as the underlying preferences with respect to location remain constant, this will be the level of the disparity. This is directly related to the ratio of the value of the amenities from Blanchard and Katz's model. The agents with the lowest willingness to pay to remain in their birth region are the first to move out of Region 1 . This causes a rise in the average willingness to pay in Region 1 and a simultaneous fall in the willingness to pay in Region 2. In this way, the unemployment disparity is indeed determined by the ratio of the value of the amenities except that in the simulation model this ratio is endogenously determined.

\subsection{Changes to unemployment insurance}

Getting back to the main discussion of unemployment disparities, there are two particularly important factors in determining the post shock equilibrium disparity: the strength of the residential preference and the level of unemployment insurance. This would correspond to changing the slope of $M$ in Figure 2 . The effect of these factors can be investigated using the model. Figure 3 shows what happens when the level of unemployment insurance is reduced from 300,000 NOK to 250,000 NOK.

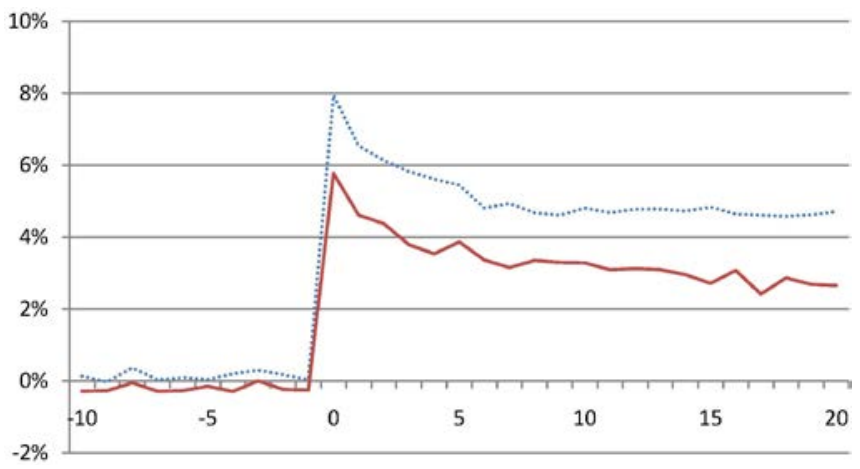

Figure 3: Unemployment differential with a $10 \%$ employment shock introduced into Region 1 at year 0 . The dotted line shows the situation with unemployment insurance of 300,000 NOK with the unbroken line showing the result when unemployment insurance is 250,000 NOK. 
The results shown in Figure 3 are in line with expectations. The reduction in unemployment insurance increases the gains which can be made from working. For some agents, this will mean that they are willing to move, even if it means that they no longer satisfy their residential site preferences. This results in a lower disparity emerging. There is another point to take notice of here. At the beginning of this section, it was assumed that commuting was unimportant. Assume for a moment that this was a reasonable assumption and that commuting was so insignificant that it could be ignored. Would it be reasonable to use such a model for policy analysis when the policy change is substantial, as in the case of a lowering of unemployment insurance by 50,000 NOK? The answer to this question is that it depends, but the result cannot be known a priori.

This point is obvious from the output of the simulation model. As stated, the simulation is run 25 times using different random seeds. In most runs, a commuting cost of $5 \mathrm{NOK}$ per $\mathrm{km}$ is sufficient to deter any significant level of commuting. However, in several runs, due to the development of wages and population, significant commuting flows take place. This is since the disparity between the unemployment insurance and the wage becomes high enough to induce a response from unemployed workers. If modelling a real world situation with a model assuming no commuting, the results could be very misleading. The model may well appear to fit the existing data well but may give completely unreasonable predictions for large policy changes. The same criticism is relevant for the opposite case where commuting flows are predicted while assuming no migration in the cases of large changes in infrastructure.

\subsection{Changes to the strength of the residential site preference}

To explore the role of the agents' preference to live in the region in which they were born, the strength of this preference was altered by adjusting the distribution of the $\beta$ parameter in the utility function. The parameter was initially uniformly distributed over the interval 0.5 to 1 . This was lowered to 0.25 to 0.75 and the simulation rerun. The result is presented in Figure 4. 


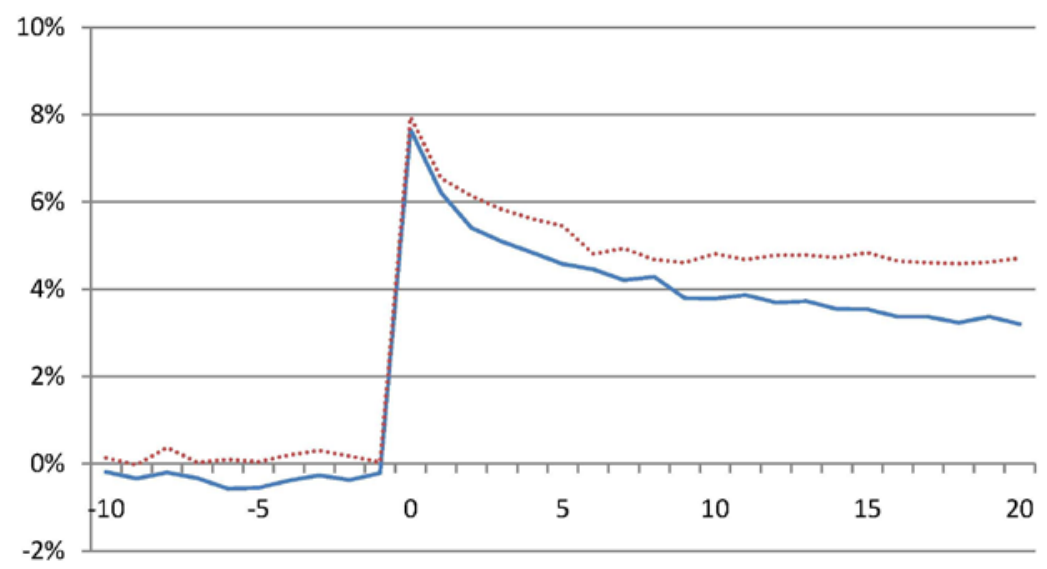

Figure 4: Unemployment differential with a $10 \%$ employment shock introduced into Region 1 at year 0 . The dotted line shows the situation where $\beta: U[0.5,1]$ with the unbroken line showing the result when $\beta \sim U[0.25,0.75]$.

Once again, the result is as expected. The reduction in the strength of the residential site preference causes a fall in the level of the equilibrium disparity. Agents are now less willing to accept an unemployment disparity to satisfy their residential site preference. The lowering was not, however, sufficient to close the disparity and the economy still stops short of full adjustment after the shock.

\subsection{The introduction of an amenity}

The discussion so far has focused on how agents in the model respond to an exogenous shock to employment in one of the regions. In relation to Figure 2, this shock relates to the position of the $D$ curves (i.e. how migration translates into unemployment disparities). The changes to unemployment insurance and the residential site preference correspond to changes in the slope of the $M$ curve (i.e. how agents respond in terms of migration to unemployment disparities). Attention will now be given to what might cause a shift in the $M$ curve. A shift in this curve would represent a situation where agents would have an incentive to migrate to another region even when employment opportunities are identically distributed. The most obvious cause of such a phenomenon would be the presence of amenities.

It is at this stage use of the $\Omega$ parameter from Equation 3 can be made. This parameter represents the willingness of agents to pay for a region specific amenity. Agents receive the benefit of this amenity only if they live in the region with the amenity. If this benefit is to be interpreted as a better climate or urban 
amenities, then it seems sensible to model a situation where there is a greater distance between the two regions. As an example, a distance of $150 \mathrm{~km}$ is used with an amenity worth 100,000 NOK. After adjusting for inflation and wages in the simulation model, this lies in the same order of magnitude as estimates by Blomquist et al. (1988) who estimated a difference in quality of life between the top-ranked and bottom-ranked US counties of $\$ 5,146$ per household per year in 1980 . Figure 5 shows what happens to the unemployment differential when an amenity worth 100,000 NOK per year to each individual living in that region is introduced to Region 1.

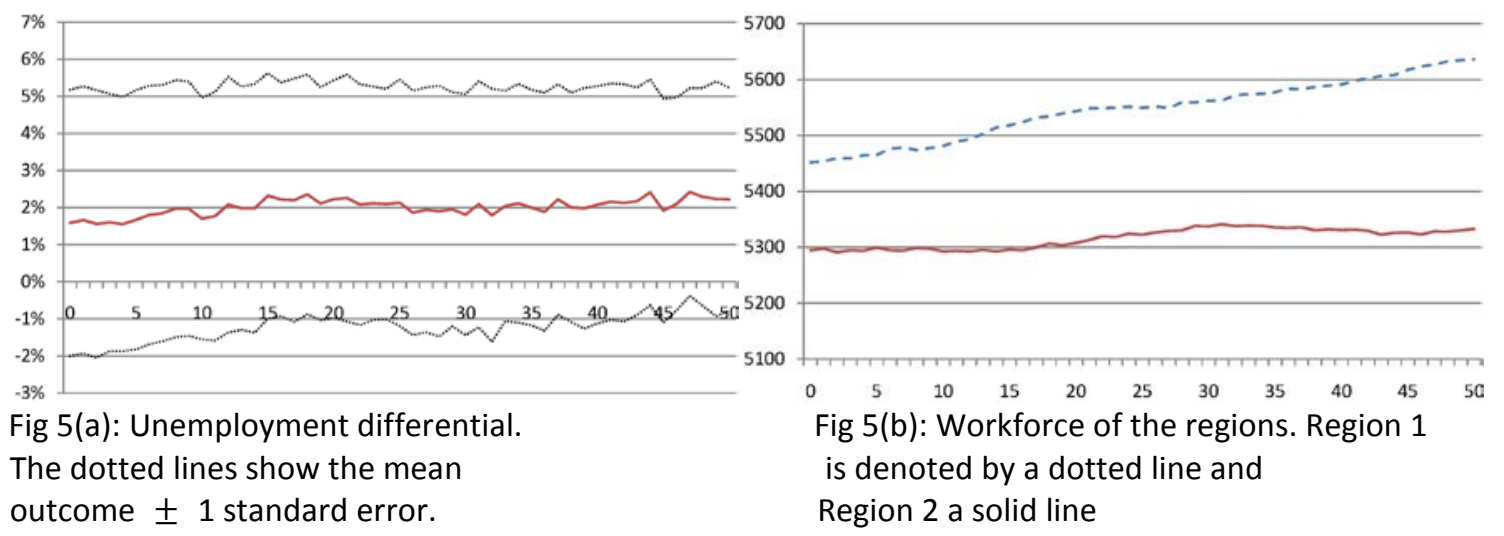

Figure 5: The effect of having an amenity worth 100,000 NOK per year in Region 1 and with 150 km between the regions.

Figure 5(a) shows how the presence of an amenity in Region 1 causes a significant unemployment disparity to emerge and persist. Agents are now willing to tolerate high unemployment in the region because they are compensated by the presence of the amenity. Figure 5(b) shows that the amenity causes the size of the workforce in Region 1 to rise whilst it stagnates in Region 2. This is since the amenity in Region 1 causes almost all of the unemployed workers in Region 2 to migrate to Region 1. Sensitivity analysis not presented here shows the same kind of effects for slightly higher or lower values of the amenity.

\subsection{The adjustment process under exogenous wages}

All of the simulation runs so far have included the wage mechanism outlined in Section 3.4. The Phillips curve mechanism used allows wages and employment to adjust to changes in unemployment. 
However, given the evidence presented in Section 2.1.3 on the inflexibility of wages, it is interesting to consider the types of outcomes which would be observed if wages were not at all sensitive to local economic conditions. Figure 6 presents the amenity experiment from Figure 5(a) along with what would have been observed with exogenous wages.

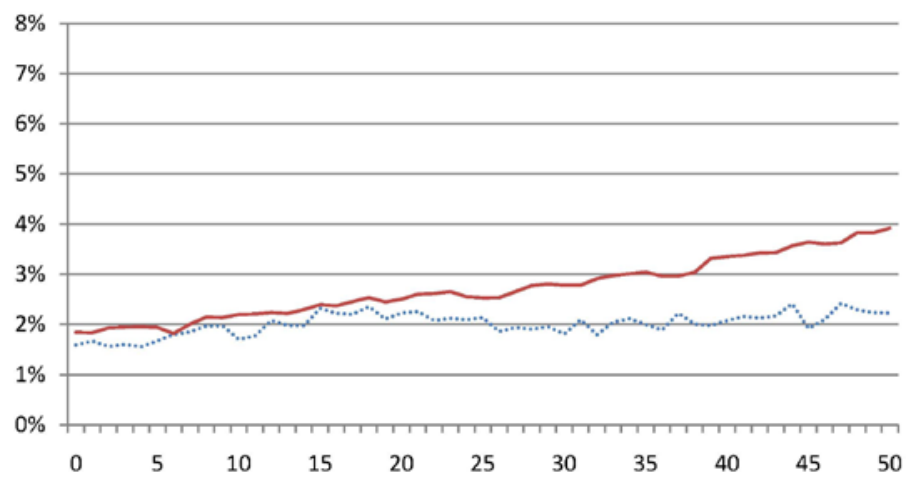

Figure 6: Unemployment differential with an amenity worth 100,000 NOK per year present in Region 1 . The dotted line gives the situation with endogenous wages with the solid line showing the outcome with exogenous wages.

The results here are as expected. With endogenous wages, as workers move to Region 1 to take advantage of the amenity, unemployment begins to rise as the supply of labour outstrips demand and wages begin to fall. This decreases the attractiveness of the area and causes the disparity to stabilise. When wages are exogenous, the only adjustment mechanism left is unemployment. Now, as workers move to Region 1 , unemployment begins to rise. This rate must rise to a sufficiently high level to deter any more migration. This leads to a higher disparity being observed. It is possible to show that exogenous wages lead to high disparities in all the simulations presented in the paper.

\subsection{The effect of distance}

One key determinant of the evolution of the regions in the model is the distance between them. In the simulation model, the distance affects both commuting and migration behaviour through the cost of commuting and agents' residential site preferences. Figure 7 presents the split between unemployment disparities, migration and commuting as the economy adjusts to the adverse employment shock under different assumptions about the distance between the regions. 


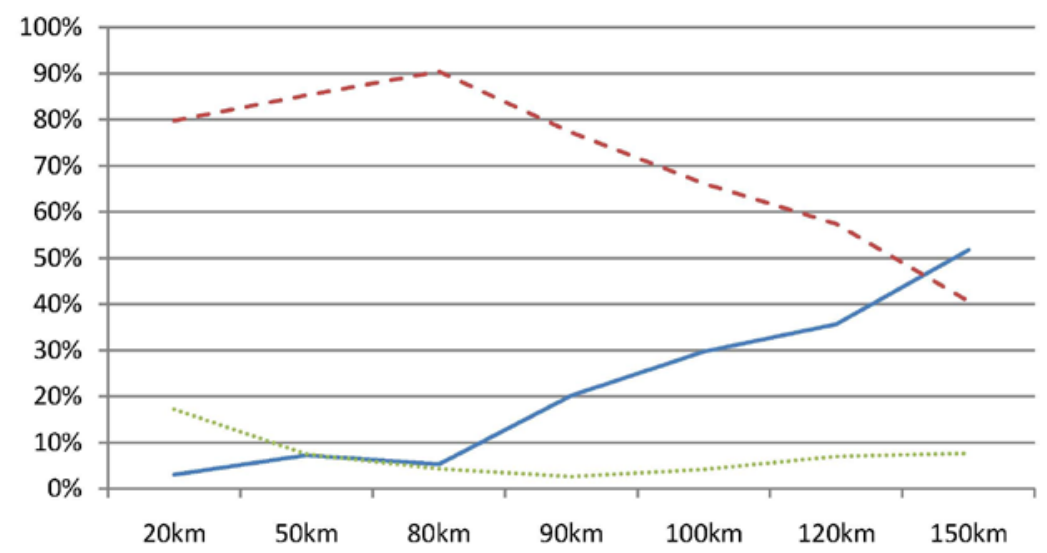

Figure 7: The split between unemployment disparity, migration and commuting in the post-shock adjustment process. Unemployment disparity denoted by a solid line, commuting by a dashed line and migration by a dotted line.

Figure 7 shows the percentage change in commuting, population and unemployment disparity after the employment shock in Region 1. This is measured by recording the average unemployment disparity, population differential and gross commuting flows before the shock, and then average over years $15-20$ after the shock has been introduced. The measure therefore represents a medium to long term adjustment. For a given geography to experience an even distribution of unemployment, excess unemployed workers in Region 1 must obtain jobs in Region 2 and either commute or migrate there. If this does not happen, an unemployment disparity will be created. As can be seen, the size of the unemployment disparity is an increasing function of distance. The increase in distance introduces friction into the adjustment mechanisms which prevents them for redistributing unemployment across the economy.

One surprising result is the role played by commuting, even over long distances. Renkow (2003; 2006; 2007) found that commuting tended to account for around $60 \%$ to $80 \%$ of the adjustment to changes in labour demand. The precise percentage is likely to depend on distance. The simulation model makes it possible to see this proportion on a more refined geographic scale than would be possible with most data sets. In the model, commuting is responsible for $60 \%$ to $80 \%$ of the adjustment for distances between 90 and $120 \mathrm{~km}$. The proportion is higher for shoter distances and lower for longer.

Part of the reason for the importance of commuting as an adjustment mechanism is that it operates in 
two distinct ways in the model. Firstly, the reduction of jobs in Region 1 increases the incentive to commute out of the region. The second way in which commuting acts to dampen the shock is that a proportion of the jobs which were removed from Region 1 were held by workers living in Region 2. The employment shock therefore causes a sharp fall in the number of commuters coming into the affected region. In this way, commuting can play an important role in the adjustment process even when commuting flows decline substantially. This is in line with Renkow $(2006 ; 2007)$ who notes that changes in labour demand can be met through changes in both the flow of in- and out-commuters. He also notes that falls in out commuting tend to play a more important role in adjusting to employment growth in rural counties than in metro counties. Despite the large role played by commuting, it behaves as expected in that it declines with distance.

Unlike in the model proposed by Blanchard and Katz (1992), migration plays only a small role in the adjustment process. In this way, the results are more consistent with the literature cited in Section 2.1.1 which also found migration playing a small role in the adjustment process in both the US and Europe. One interesting feature of the behaviour of migration is that it does not strictly decline with distance. The level of migration is relatively high for low distances as workers choose to save on commuting costs by moving. As the distance increases, concerns over residential site preferences begins to dominate commuting costs and commuting begins to play a more important role. As the distance increases further, commuting costs begin to dominate once again for some agents and the proportion migrating increases.

Another point to note is the role played by unemployment disparities. For distances of under $80 \mathrm{~km}$, there is almost no disparity. As the distance moves beyond this level, the shock causes successively larger unemployment disparities to appear. For a distance of $150 \mathrm{~km}$, the majority of the unemployment shock affects only region 1 with less than half of the impact being redistributed through commuting and migration.

The most important point to take from this part of the analysis is the integral relationship between commuting, migration and unemployment. It has already been shown empirically that commuting plays an important part in the adjustment process, however the simulation model has shown that this finding holds 
over a wide range of distances. The clear implication is that any study ignoring commuting must have clear reasons to believe that no commuting can or will take place between the regions under consideration. While migration plays only a small role in the adjustment process, it it does still play a role. For short distances, migration accounted for around $15 \%$ of the adjustment. This declines for the middle of the range considered and then rises again to around $8 \%$. To ignore this would lead to an overestimation of commuting flows and/or unemployment disparities.

\section{An empirical example}

This example will concentrate on unemployment disparities in south west Norway. Figure 8 shows a map of average unemployment rates between 1988 and 2007 in this area.

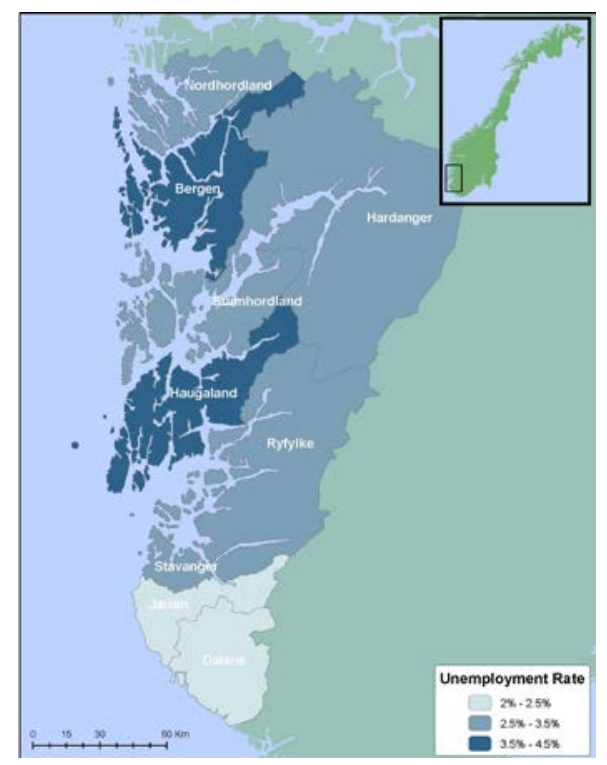

Figure 8: Average unemployment rates in south-west Norway for the period 1988-2007. The map is based on data from Statistics Norway and the authors' calculations.

The area consists of a number of urban and rural regions. The main employment centres are Bergen, Stavanger and Haugaland. These regions have also tended to experience higher rates of unemployment. While the map gives a general picture of unemployment patterns it gives less information about the development of the unemployment rates over time. To investigate this, the regions were classified as either urban or rural. Two regions, Jæren and Nordhordland do not fall into either of these categories and are 
treated separately. Unemployment rates for the urban/rural regions and for Jæren and Nordhordland are presented in Figure 9.

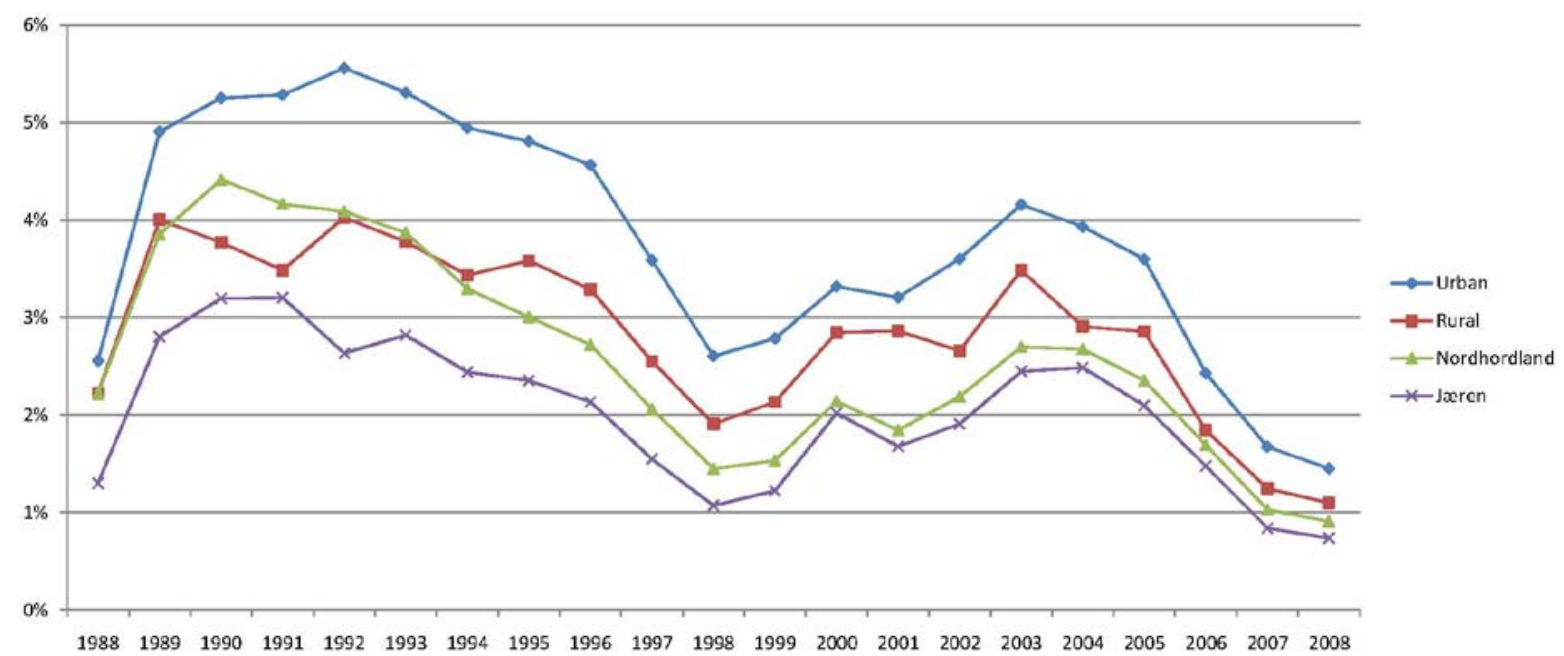

Figure 9: Unemployment rates over time for different categories of regions based on data from Statistics Norway and the authors' calculations.

The first point to note is that out of all the categories, urban areas have always experienced the highest unemployment. Rural areas have experienced a moderate level of unemployment. Jæren has experienced the lowest level of unemployment over the period. It is what could be described as a commuter region with large number of its residents commuting to the Stavanger region. Nordhordland is not quite like any of these regions over the whole time frame. From 1988 to 1994, the unemployment rate in Nordhordland is close to the rate of the rural counties. In 1994, the Nordhordland bridge was opened. This connected the region to the city of Bergen and opened the possibility of daily commuting. After 1994, the unemployment rate begins to fall relative to the rural areas and then is approximately equal to Jæren's unemployment rate.

Today, both Nordhordland and Jæren are considered commuter regions as both are within commuting distance of a major urban area i.e. Bergen and Stavanger respectively. Renkow and Hoover (2000) make a similar distinction between rural areas and rural areas adjacent to metro areas. Jæren is is clearly adjacent to Stavanger for the entirety of the period under consideration. Nordhordland presents a slightly more difficult case. While geographically adjacent to Bergen, prior to the opening of the bridge, daily commuting was not a feasible option for most people due to the presence of a fjord. Nordhordland could thus be classed as rural. 
After the construction of the bridge, it could be considered 'adjacent' to Bergen. Correspondingly, it would be expected that out commuting would rise. Renkow and Hoover (2000) do not directly consider how changes in the demand for labour may affect the spatial pattern of unemployment. The data presented here suggest that particular types of regions, e.g. rural and adjacent to a metro area, may also experience particular patterns of unemployment in relation to other regions.

The simulation model gives some information about the time taken to adjust; something not easily obtained with standard analytic approaches. The opening of the Nordhordland bridge causes a fall in the generalised cost of commuting. This is similar to the scenario presented in Figure 0 . In that figure, the economy takes around 5 years to adjust to its new equilibrium position. This is the around the same length of time it takes the unemployment rate in Nordhordland to reach its new equilibrium position relative to the other regions. The unemployment rate does not converge on the unemployment rate of the region it is connected to as in Figure 1. This is not surprising since that scenario assumes that there are no asymmetries in the system other than the employment shocks.

There are other patterns in Figure 9 which are similar to those generated by the simulation model. In this way, the model can aid interpretation of the empirical observations. Consider first the employment disparity between the urban and rural regions. The urban areas have experienced an unemployment rate which has been consistently higher than in rural regions. This pattern looks very similar to Figure 5 where the presence of an amenity in one region causes it to have a consistently higher level of unemployment; a persistent disparity of two percentage points in this particular example. In the case of the empirical example, the amenities would be the net benefits of living in an urban area. Although not shown here, the population development in the rural and urban areas match the population development shown in Figure 5(b). Unemployed workers in rural areas tend to leave for the cities. As a result rural areas experience very low levels of unemployment and a stagnating or declining population, while the population of the cities grows at the same time as they experience higher levels of unemployment. 
The most likely reason that the commuter areas do not behave like urban areas is that urban areas have more differentiated labour markets and higher wage jobs. This can give a situation where it is profitable to commute from a commuter area to a city but not in the opposite direction. This would lead commuter regions to have lower unemployment rates than the urban areas they are connected to. Such a situation could easily be modelled in the simulation by introducing heterogeneous jobs and workers where high wage, specialised jobs are concentrated in one region. In addition to this asymmetric commuting effect, the presence of higher wage jobs may also encourage immigration despite high unemployment as in Harris and Todaro (1970). This, combined with amenity migration, could lead to significant and persistent unemployment disparities.

\subsection{Policy implications}

The simulation model has allowed the simultaneous modelling of commuting, migration, equilibrium disparities and disequilibrium disparities. Understanding the relationships between these concepts is essential in developing effective regional policy. Figure 9 shows that unemployment differentials have persisted over a substantial period of time. However, areas with the highest unemployment are also the most prosperous, expanding areas. The differential therefore represents an equilibrium disparity. Attempts to close such disparities by stimulating employment in the high unemployment areas are misguided as it is the underlying ratio of amenities which causes the disparity and not an unfavourable asymmetry in employment opportunities.

Increasing the connectivity of regions can be a useful policy tool. If the regions are of a similar type, e.g. both rural, then this can reduce or eliminate unemployment disparities. If the regions are rural and urban, then this outcome is less likely and unemployment disparities may actually increase, as shown in Figure 9 with the introduction of the Nordhordland bridge. One possible explanation of what happens in that example is that the bridge allowed people to satisfy their residential site preferences while still being able to access the 
urban labour market and amenities. Figure 4 has shown that workers in the simulation model were willing to tolerate higher rates of unemployment to satisfy this location preference. Allowing workers to satisfy their residential site preferences without having to tolerate higher unemployment in such a context would increase their welfare. It would also help to ensure the sustainability of more rural regions by allowing workers to gain employment without having to migrate out of the region. This may be a more worthwhile aim than trying to achieve a more even distribution of unemployment.

\section{Conclusion}

This paper started out with two observations: that regional unemployment disparities have been remarkably persistent in many countries around the world and that attempts to model such disparities almost always result in unsatisfactory treatment of the simultaneity between commuting and migration. One of the reasons for this is that any analytical model of unemployment disparities quickly becomes intractable when commuting and migration are considered simultaneously. The inability to derive robust results analytically makes empirical research more difficult.

This paper has adopted a microsimulation approach based on ideas from the field of agent-based computational economics. A model was successfully constructed which allows situations with commuting, migration, frictional unemployment and equilibrium unemployment to be considered. The model has been constructed in such a way that it is possible to use it to analyse a wide range of situations. It is also able to go beyond what is possible with intuition or standard analytic approaches. Consider Section 4.6, looking at the effect of distance on the split between unemployment, migration and commuting. Data availability and suitability are likely to impose constraints on obtaining such a result empirically while an analytical model would have to impose a large number of fairly restrictive assumptions.

Given the positive results obtained here it appears that this class of model could prove useful within the field of regional economics. The model developed in this paper can be used in a number of ways. Firstly, it 
is capable of showing what kinds of results are produced in a given situation. While this is not the equivalent of a mathematical proof, it may be the best that can be achieved given the complexity of the regional interaction process. From a more applied perspective, the model can be used to guide empirical research. This could take the form of giving suggestions of signs and sizes of effects. This can either provide some benchmark against which to evaluate empirical results or, in the case of Bayesian statistics, incorporated directly into the model.

Alternatively, the data generated by the simulations could be used to evaluate alternative empirical models and methods as well as generating estimates of the size and power of various tests. Such guidance can be invaluable when considering complex problems such as regional development. In the case of Figure 6 , the model produced similar results to those presented in Renkow $(2003 ; 2006 ; 2007)$ with regard to the role played by commuting in the process of adjustment to changes in the demand for labour. However, in addition to reproducing the sort of effects measured empirically, the model provided predictions about how this would vary with distance. Data availability may not have allowed such predictions to be made empirically.

The empirical example gives an indication of how the model corresponds to empirical observations. Figure 9 shows that an unemployment disparity of around 1.5\% exists between the urban and rural areas. Figure $5($ a) shows that an amenity worth 100,000 NOK in a region gives a disparity of around $2 \%$. This gives an indication of how different factors within the model are traded off and what order of magnitude an amenity would need to be to generate this kind of disparity. It is difficult to see how this could be achieved in an analytical framework.

\section{References}

Abraham, F. 1996, "Regional adjustment and wage flexibility in the European Union", Regional Science and Urban Economics, vol. 26, no. 1, pp. 51-75.

Bartik, T. 1993, "Who benefits from local job growth: migrants or the original residents?", Regional Studies, vol. 27, no. 4, pp. 297-311.

Bentivogli, C. \& Pagano, P. 1999, "Regional Disparities and Labour Mobility: the Euro-11 versus the USA", Labour, vol. 13, no. 3, pp. 737-760. 
Berger, M.C., Blomquist, G.C. \& Sabirianova Peter, K. 2008, "Compensating differentials in emerging labor and housing markets: Estimates of quality of life in Russian cities", J ournal of Urban Economics, vol. 63, no. 1, pp. 25-55.

Blanchard, O.J . \& Katz, L.F. 1992, "Regional Evolutions", Brookings Papers on Economic Activity, vol. 1, no. Macroeconomics, pp. 1-75.

Blanchflower, D.G. \& Oswald, A.J . 1994, The Wage Curve, First edn, MIT Press.

Blomquist, G.C., Berger, M.C. \& Hoehn, J.P. 1988, "New Estimates of Quality of Life in Urban Areas", The American Economic Review, vol. 78, no. 1, pp. 89-107.

Buettner, T. 2007, "Unemployment disparities and regional wage flexibility: comparing EU members and EU-accession countries", Empirica, vol. 34, no. 4, pp. 287-297.

Decressin, J . \& Fatás, A. 1995, "Regional labor market dynamics in Europe", European Economic Review, vol. 39, no. 9, pp. 1627-1655.

Diamond, C.A. \& Simon, C.J. 1990, "Industrial Specialization and the Returns to Labor", Journal of Labor Economics, vol. 8, no. 2, pp. 175-201.

Elhorst, J.P. 2003, "The Mystery of Regional Unemployment Differentials: Theoretical and Empirical Explanations", Journal of Economic Surveys, vol. 17, no. 5, pp. 709-748.

Evans, P. \& McCormick, B. 1994, "The New Pattern of Regional Unemployment: Causes and Policy Significance", The Economic Journal, vol. 104, no. 424, pp. 633-647.

Fidrmuc, J. 2004, "Migration and regional adjustment to asymmetric shocks in transition economies", J ournal of Comparative Economics, vol. 32, no. 2, pp. 230-247.

Green, A.E., Hogarth, T. \& Shackleton, R.E. 1999, "Longer distance commuting as a substitute for migration in Britain: a review of trends, issues and implications", International Journal of Population Geography, vol. 5, no. 1, pp. 49-67.

Harris, J.R. \& Todaro, M.P. 1970, "Migration, Unemployment and Development: A Two-Sector Analysis", The American Economic Review, vol. 60, no. 1, pp. 126-142.

Jimeno, J.F. \& Bentolila, S. 1998, "Regional unemployment persistence (Spain, 1976-1994)", Labour Economics, vol. 5, no. 1, pp. 25-51.

López-Bazo, E., Barrio, T.D. \& Artís, M. 2005, "Geographical distribution of unemployment in Spain", Regional Studies, vol. 39, no. 3, pp. 305.

Maoh, H. \& Kanaroglou, P. 2007, "Business establishment mobility behavior in urban areas: a microanalytical model for the City of Hamilton in Ontario, Canada", J ournal of Geographical Systems, vol. 9, no. 3, pp. 229-252.

Marston, S.T. 1985, "Two Views of the Geographic Distribution of Unemployment", The Quarterly J ournal of Economics, vol. 100, no. 1, pp. 57-79.

Mulhern, A. \& Watson, J.G. 2009, "Spanish Internal Migration: Is there Anything New to Say?", Spatial Economic Analysis, vol. 4, no. 1, pp. 103-120.

Partridge, M.D. \& Rickman, D.S. 1997a, "The Dispersion of US State Unemployment Rates: The Role of Market and Non-market Equilibrium Factors", Regional Studies: The Journal of the Regional Studies Association, vol. 31, no. 6, pp. 593-606.

Partridge, M.D. \& Rickman, D.S. 1997b, "Has the wage curve nullified the Harris-Todaro model? Further US evidence", Economics Letters, vol. 54, no. 3, pp. 277-282.

Partridge, M.D. \& Rickman, D.S. 2003, "The waxing and waning of regional economies: the chicken-egg question of jobs versus people", J ournal of Urban Economics, vol. 53, no. 1, pp. 76-97.

Partridge, M.D. \& Rickman, D.S. 2006, "Fluctuations in aggregate US migration flows and regional labor market flexibility", Southern Economic Journal, vol. 72, no. 4, pp. 958-980.

Partridge, M.D. \& Rickman, D.S. 2007, "Canadian regional labour market evolutions: a long-run restrictions SVAR analysis", Applied Economics, vol. 99999, no. 1, pp. 1-17.

Partridge, M.D., Rickman, D.S. \& Li, H. 2009, "Who Wins From Local Economic Development?: A Supply Decomposition of US County Employment Growth", Economic Development Quarterly, vol. 23, no. 1, pp. 13-27.

Puhani, P.A. 2001, "Labour Mobility: An Adjustment Mechanism in Euroland? Empirical Evidence for Western Germany, France and Italy", German Economic Review, vol. 2, no. 2, pp. 127-140.

Renkow, M. 2006, "Employment growth and the allocation of new jobs: Evidence from the South", Review of Regional Studies, vol. 36, no. 1, pp. 121-139.

Renkow, M. 2007, "Employment Growth and the Allocation of New J obs: Spatial Spillovers of Economic and Fiscal Impacts", Review of Agricultural Economics, vol. 29, no. 3, pp. 396-402. 
Renkow, M. 2003, "Employment growth, worker mobility, and rural economic development", American J ournal of Agricultural Economics, vol. 85, no. 2, pp. 503-513.

Renkow, M. \& Hoover, D. 2000, "Commuting, migration, and rural-urban population dynamics", Journal of Regional Science, vol. 40, no. 2, pp. 261-287.

Rosenzweig, M.R. \& Stark, O. 1989, "Consumption smoothing, migration, and marriage: evidence from rural India", The Journal of Political Economy, vol. 97, no. 4, pp. 905-926.

Rowthorn, R. \& Glyn, A. 2006, "Convergence and stability in US employment rates", Contributions to Macroeconomics, vol. 6, no. 1, pp. 1-42.

Sandow, E. 2008, "Commuting behaviour in sparsely populated areas: evidence from northern Sweden", J ournal of Transport Geography, vol. 16, no. 1, pp. 14-27.

Schafer, A. \& Victor, D.G. 2000, "The future mobility of the world population", Transportation Research Part A, vol. 34, no. 3, pp. 171-205.

Siebert, H. 1997, "Labor Market Rigidities: At the Root of Unemployment in Europe", The J ournal of Economic Perspectives, vol. 11, no. 3, pp. 37-54.

Tuck, B., Berman, M. \& Hill, A. 2009, "Local amenities, unobserved quality, and market clearing: Adjusting teacher compensation to provide equal education opportunities", Economics of Education Review, vol. 28, no. 1, pp. 58-66.

van Dijk, J. \& Pellenbarg, P.H. 2000, "Firm relocation decisions in The Netherlands: An ordered logit approach", Papers in Regional Science, vol. 79, no. 2, pp. 191-219.

van Ommeren, J., Rietveld, P. \& Nijkamp, P. 1999, "J ob Moving, Residential Moving, and Commuting: A Search Perspective", J ournal of Urban Economics, vol. 46, no. 2, pp. 230-253.

\section{Appendix A}

\section{Parameter/Variable Table}

Table 1: Default Parameter/Variable Values.

\begin{tabular}{|c|c|}
\hline Parameter/Variable & Value \\
\hline$a$ & 0.9 \\
\hline$b$ & $4.4 \cdot 10^{-5}$ \\
\hline$c$ & 1.10154 \\
\hline$\sigma$ & $100,000 \mathrm{NOK}$ \\
\hline$\alpha$ & 0.01 \\
\hline$\beta$ & 0.005 \\
\hline$\Omega$ & $\sim U[0.5,1]$ \\
\hline$\lambda$ & 0 \\
\hline$\rho$ & 0.1 \\
\hline$\eta_{1}$ & 0.07 \\
\hline$\eta_{2}$ & 0.1 \\
\hline Commuting Cost per km & 0.05 \\
\hline Unemployment Insurance & $2.5 \mathrm{NOK}$ \\
\hline Initial Wage & p.a. \\
\hline & $400,000 \mathrm{NOK}$ \\
\hline Initial Unemployment & p.a. \\
\hline Initial Population & $5 \%$ \\
\hline Average Population & 16,000 \\
\hline
\end{tabular}

